\title{
Defining the IT Curriculum: The Results of the Past 3 Years
}

\author{
Barry M. Lunt and \\ Joseph J. Ekstrom \\ Brigham Young Univer- \\ sity, Provo, UT, USA
}

\author{
luntb@byu.edu \\ jekstrom@byu.edu
}

\author{
Edith A. Lawson \\ Rochester Institute \\ of Technology, \\ Rochester, NY, USA
}

eal@it.rit.edu

\author{
Reza Kamali \\ Purdue University Calu- \\ met, Hammond, IN, USA
}

kamalir@calumet.purdue.edu

\author{
Jacob Miller and Sandra Gorka \\ Pennsylvania College of Technol- \\ ogy, Williamsport, PA, USA \\ imiller3@pct.edu sgorka@pct.edu
}

\author{
Han Reichgelt \\ Georgia Southern University, \\ Statesboro, GA, USA \\ han@georgiasouthern.edu
}

\begin{abstract}
Efforts to define IT curriculum and accreditation standards began at the first Conference on Information Technology Curriculum (CITC-1) in December 2001, which included representatives from 15 Information Technology (IT) programs at four-year schools in the United States, and representatives from the Association for Computing Machinery (ACM), the Institute for Electrical and Electronic Engineers (IEEE), and the Accreditation Board for Engineering and Technology (ABET). Since this conference, this work has been ongoing at CITC-2 (April 2002), CITC-3 (September 2002), and CITC-4 (October 2003), and through committee work which has progressed between these conferences. The three main thrusts of this work have been to define standards for accreditation of IT programs, to define a model curriculum for IT programs, and to distinguish IT programs from the most closely-related academic programs, such as Information Systems and Computer Science. Membership in SIGITE (Special Interest Group on Information Technology Education) of the ACM is now over 300 members and represents most 4-year IT programs and several 2-year IT programs in the United States; the outcome of these three main thrusts should therefore be of wide interest to all those in related programs or at institutions considering forming a similar program. This paper gives some of the details of the results of the work on these three thrusts.
\end{abstract}

Keywords: Information Technology, Curriculum, information systems, computer science

Material published as part of this journal, either on-line or in print, is copyrighted by Informing Science. Permission to make digital or paper copy of part or all of these works for personal or classroom use is granted without fee provided that the copies are not made or distributed for profit or commercial advantage AND that copies 1) bear this notice in full and 2) give the full citation on the first page. It is permissible to abstract these works so long as credit is given. To copy in all other cases or to republish or to post on a server or to redistribute to lists requires specific permission from the publisher at Publisher@InformingScience.org

\section{Introduction}

In the first week of December of 2001 representatives from 15 undergraduate information technology (IT) programs from colleges/universities across the country gathered together near Provo, Utah, to develop a community and begin to establish academic standards 
for this rapidly growing discipline. This first Conference on Information Technology Curriculum (CITC-1) was also attended by representatives from two professional societies, the Association for Computing Machine (ACM) and the Institute of Electrical and Electronics Engineers, Inc. (IEEE), and also the Accreditation Board for Engineering and Technology, Inc. (ABET). This invitational conference was the culmination of an effort begun several months earlier by five of these universities who had formed a steering committee to organize a response from existing IT programs to several initiatives to define the academic discipline of IT. The steering committee wanted to ensure that the input of existing programs played a significant role in the definition of the field.

A formal society and three main committees were formed by the attendees of CITC-1. The society was the Society for Information Technology Education (SITE); one of the committees formed was the executive board for SITE, composed of a president, vice-president, secretary, treasurer, regional representatives, and an activities chairperson. The other two committees formed were the IT Curriculum Committee, including subcommittees for 4-year and 2-year programs, and the IT Accreditation Committee, also including subcommittees for 4-year and 2-year programs.

The development of IT as an academic discipline is similar to the process that computer science (CS) went through in the 70's and 80's. In fact, looking at the placement of CS programs in academic institutions around the U.S. illustrates the debate that swirled around the discipline as its core was being defined. Some CS programs are in departments of mathematics, others are in engineering schools, and many others have become mainstay programs within newly emerging colleges of computing.

Information technology, as it is practiced at this moment in its evolution, reflects similar growing pains. IT programs exist in colleges of computing, in CS departments, in schools of technology, and in business schools. Professors of information technology possess degrees in information systems, electronics, communications, graphics arts, economics, mathematics, computer science, and other disciplines. Few to none of them have a degree in information technology.

It should be acknowledged here that IT has two substantially different interpretations, and that these should be clarified. Information Technology (IT) in its broadest sense encompasses all aspects of computing technology. IT, as an academic discipline, focuses on meeting the needs of users within an organizational and societal context through the selection, creation, application, integration and administration of computing technologies.

\section{Procedure}

The participants of CITC-1 participated in a Delphi study. A Delphi study is characterized by questions being asked of experts, who then respond freely to them. Their responses to the questions are shared with other experts, who then may modify their previous responses as they feel necessary. This sharing repeats until the opinions of the experts appear to be converging. (Brown, 1968; Dalkey, 1967, 1969; Dalkey, \& Helmer, 1951; Dalkey, Rourke, Lewis, \& Snyder, 1972).

The format of the Delphi study was chosen due to the fact that the relevant experts (the conference attendees) were all co-located. They were judged experts because all had worked in IT prior to teaching, and all were familiar with the closely related computing disciplines of Computer Science and Information Systems. Each participant was issued a pad of self-adhesive sticky notes and a blunt felt-tip marker. Then the entire group was given 20 minutes to generate as many topics as they could, one topic per sticky note. As each participant created a small pile of topics, they were encouraged to spread them out on several tables that were at the front of the room. This way, each participant could see ideas from other participants, further spurring ideas of their own. At the end of the 20 minutes, everyone had pretty well exhausted their ideas, and nearly 700 sticky notes had ideas for topics in an IT curriculum. 
The second stage of the exercise was an unconstrained organization of the topics into groups. All attendees participated in moving the notes into groups, and after about 30 more minutes, everyone agreed that the notes in each group belonged there. After this was completed, the sticky notes were gathered in their groups, and a spreadsheet was filled out with one column for each group.

After some additional organization of the topics in the categories, the entire output was reduced to 34 topic areas. Some of the topic areas were later found to be so closely related as to be basically inseparable, so they were combined.

At the conclusion of this editing work (about 2 weeks after the conference), the entire edited spreadsheet was sent to all conference attendees via email, and further feedback was sought and incorporated.

Additionally, many of the participating institutions conducted similar Delphi studies with their Industry Advisory Board (IAB) members. IABs are made up of practicing professionals with ties to the academic institution. Through these additional studies, much information was gained from practicing IT professionals working in the "real world", and their input was folded into the work of the IT curriculum committee through the members of that committee. It should be noted there that the input from IAB members was highly convergent with the information generated at CITC1, which indicates a great deal of agreement between practicing IT professionals and IT academics.

\section{Results}

The results of these Delphi studies were very significant in several ways: 1) representatives from 15 universities with 4-year IT programs had participated - this represents a significant portion of the programs in the nation; 2) representatives from three professional organizations were also in attendance - these were three of the most relevant; 3) representatives from several institutions' IABs were involved and provided valuable input from the "real world"; and 4) each participant had ample opportunity to share all their thoughts, both as to topics and as to organization, and to get feedback from other participants. Table 1 presents a list of the topics, ordered by the number of times mentioned in the study.

\begin{tabular}{|c|l|c|l|c|l|}
\hline \multicolumn{5}{|c|}{ Table 1: Topic areas in an IT curriculum defining topic area } \\
\hline$\#$ & \multicolumn{1}{|c|}{ Topic Area } & $\#$ & \multicolumn{1}{c|}{ Topic Area } & $\#$ & \multicolumn{1}{c|}{ Topic Area } \\
\hline 1 & Networking & 10 & Systems design & 19 & Holistic \\
\hline 2 & Human communications & 11 & $\begin{array}{l}\text { Hardware: architecture } \\
\text { \& circuits }\end{array}$ & 20 & Information content \\
\hline 3 & Software & 12 & $\begin{array}{l}\text { Human-computer inter- } \\
\text { facing }\end{array}$ & 21 & Social factors \\
\hline 4 & Web system design & 13 & User advocacy & 22 & System administration \\
\hline 5 & Database & 14 & $\begin{array}{l}\text { Thinking/problem solv- } \\
\text { ing }\end{array}$ & 23 & General education \\
\hline 6 & Project management & 15 & Teamwork & 24 & Evaluation \\
\hline 7 & Digital communications & 16 & Enterprise topics & 25 & Physics \\
\hline 8 & Data security/privacy & 17 & Ethics & 26 & Graphics \\
\hline 9 & Math & 18 & Embedded systems & 27 & Co-ops \\
\hline
\end{tabular}

Another way to look at the results of these studies is to organize the topic areas into four categories typical in most curricula: General education, Related courses, Professional courses, and Core courses. Table 2 gives one way of doing this. 


\begin{tabular}{|l|l|l|l|l|}
\hline \multicolumn{5}{|c|}{ Table 2: Organizing the main topic areas into four categories of course offering } \\
\hline Ranking & $\begin{array}{c}\text { General } \\
\text { Education }\end{array}$ & Related Courses & $\begin{array}{c}\text { Professional } \\
\text { Courses }\end{array}$ & \multicolumn{1}{|c|}{ Core Courses } \\
\hline 1 & Math & Hardware: arch. \& cir. & Human communications & Networking \\
\hline 2 & Holistic & Thinking/prob. solv. & Project management & Software \\
\hline 3 & $\begin{array}{l}\text { General educa- } \\
\text { tion }\end{array}$ & Embedded systems & Teamwork & Web systems design \\
\hline 4 & Physics & Information content & Enterprise topics & Database \\
\hline 5 & & System administration & Ethics & Digital communication \\
\hline 6 & & Evaluation & Social factors & Data security/privacy \\
\hline 7 & & Graphics & Co-ops & $\begin{array}{l}\text { Systems design } \\
\text { tion }\end{array}$ \\
\hline 8 & & & & User advocacy \\
\hline 9 & & & & \\
\hline
\end{tabular}

In each column, the ranking is determined by the number of times that topic area came up in the studies. Table 2 gives insight into one way of defining an IT curriculum. The topic areas with high rankings indicates a strong number of mentions for the Core Courses, and indicates to these authors that all IT programs should consist of at least one course in at least the top 4 of these areas. It is these topics, in combination, that define the domain of Information Technology. These topic areas, later termed IT pillars, are: networking, software, web systems design, databases, and human-computer interaction (HCI).

After the Core Courses, IT programs could select from the Professional Courses and Related Courses to give their program the unique emphasis they feel is most important for their customers. This would give many strong IT programs across the country, each with a common IT core and an additional focus or flavor unique to each institution.

Most university majors also have sub-specializations within the major. Table 2 can also be used to help define these possible emphases for each IT program.

Finally, Table 2 shows that there is a strong need for a math foundation, which has been defined for IT to mean algebra, discrete math, and statistics. Also, IT students should take at least one course in a lab science, such as physics, chemistry, or biology.

\section{Differentiating from Related Disciplines}

"Computer science is a discipline that involves the understanding and design of computers and computational processes. In its most general form it is concerned with the understanding of information transfer and transformation. Particular interest is placed on making processes efficient and endowing them with some form of intelligence. The discipline ranges from theoretical studies of algorithms to practical problems of implementation in terms of computational hardware and software. A central focus is on processes for handling and manipulating information. Thus, the discipline spans both advancing the fundamental understanding of algorithms and information processes in general as well as the practical design of efficient reliable software and hardware to meet given specifications..."'(CSAB, 1997)

"Information systems specialists focus on integrating information technology solutions and business processes to meet the information needs of businesses and other organizations and enable organizations to achieve their objectives in an effective and efficient way. This discipline's perspective on 'Information Technology' emphasizes information, and sees technology as an instrument to enable the generation, processing and distribution of needed information. Professionals in this discipline are primarily concerned with the information that computer systems can provide to 
aid the organization in defining and achieving its goals and the processes that organizations can implement using information technology." (Joint Task Force, 2004)

In a paper published in the proceedings of CITC-3 (Lunt et al., 2002), and later refined and published in the proceedings of CIEC-2003 (Lunt et al., 2003b), Lunt et al. helped a great deal in defining the academic discipline of information technology, especially with relation to its most closely related disciplines of computer science (CS) and information systems (IS). This effort was further developed by Reichgelt et al. in a paper published in the Journal of Information Technology Education (Reichgelt et al., 2004). The first two studies included other related disciplines such as information science, electrical engineering, electronic/telecommunications engineering technology, and computer engineering/ engineering technology, and were conducted at 12 institutions that had programs in IT and at least two other related disciplines. A full listing of the institutions included in the study is contained in the second part of the Appendix. The study by Reichgelt et al. included the related disciplines of computer science and information systems.

These studies consisted of counting the semester credit hours required to graduate in each discipline, and categorizing these requirements into the general areas of business (Bus); electronics \& signals (E\&S); hardware (Hdwe); interpersonal communications (IntpComm); networking, web systems, databases (N,W,D); physics, math, chemistry ( $\mathrm{Ph}, \mathrm{Ma}, \mathrm{Ch})$; and software (Sftwe).

For IT, the two most closely-related disciplines are CS and IS. Figures 1, 2 and 3 below provide an excellent comparison of these three academic disciplines, as described in the studies cited. It can be seen from Figures 1, 2 and 3 that the dominant category for CS is Sftwe (software), as would be expected. The dominant category for IS is Bus (business). The dominant area for IT is N,W,D (networks, webs systems, and databases).

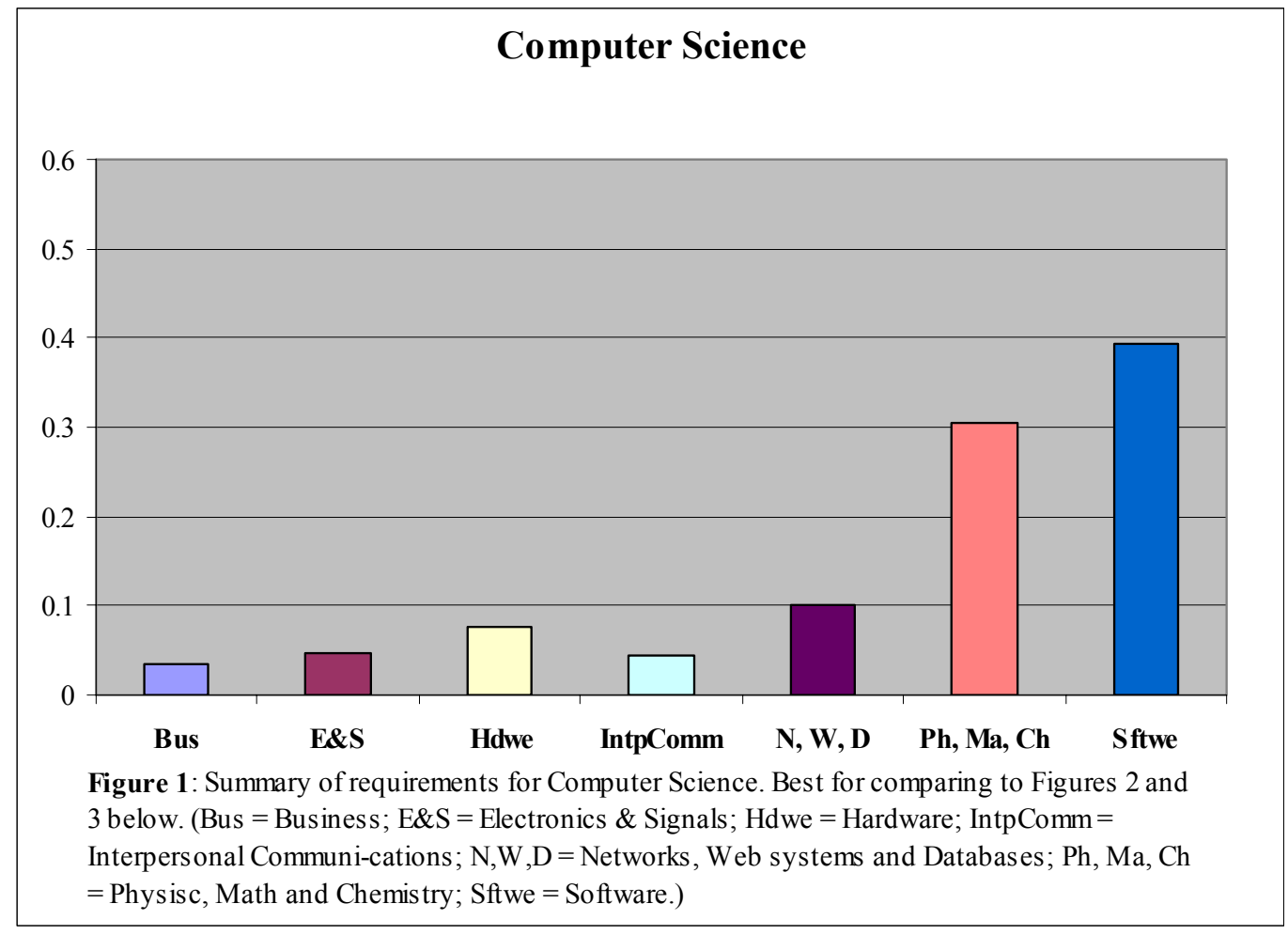



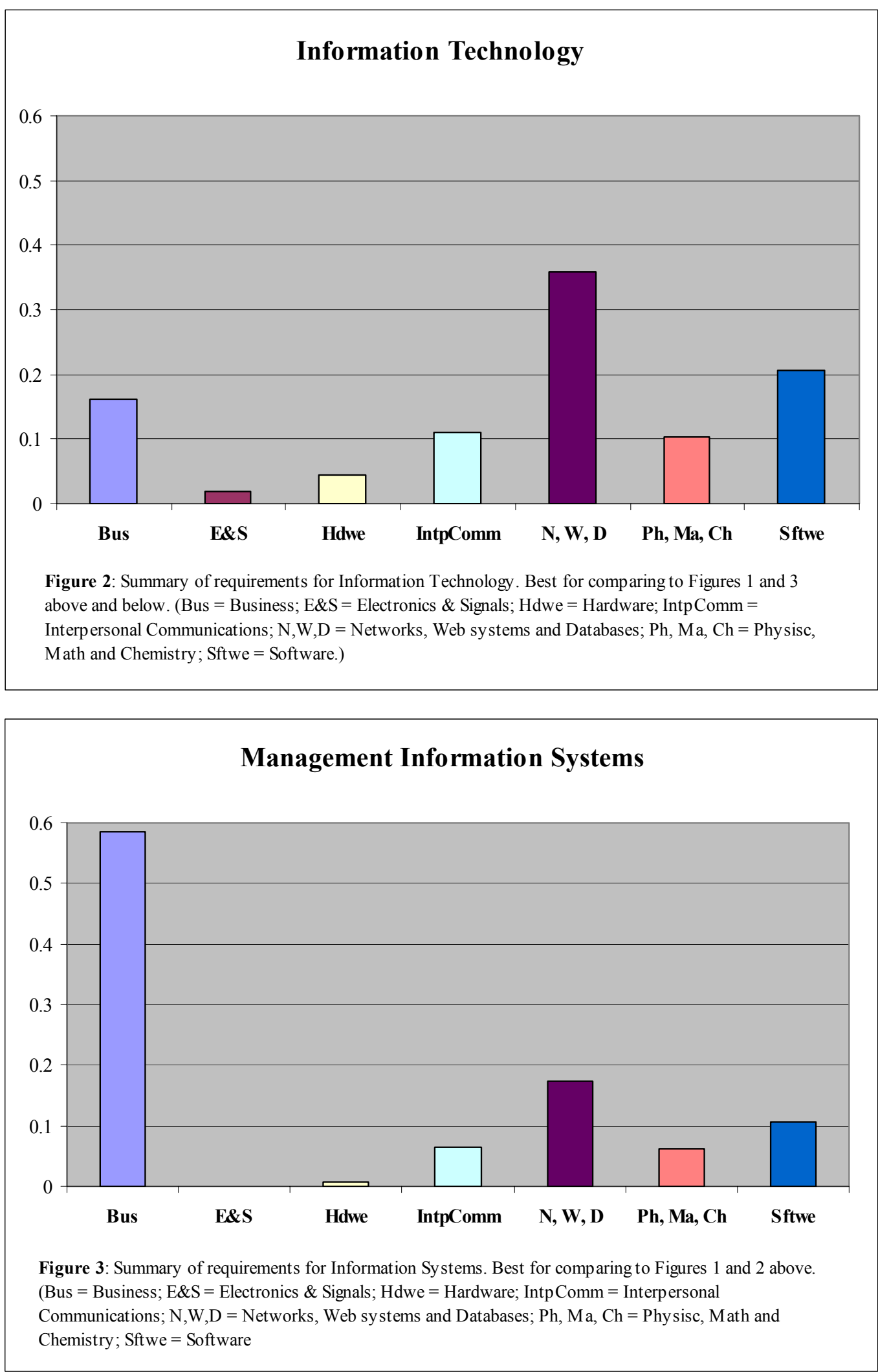


\section{Computing Discipline Definitions}

Before the 1990s, computer science and information systems were essentially the only formally defined computing disciplines. Computer science had defined itself in the volumes, Curriculum '68, Curriculum '78, and Computing Curricula 1991. Information systems has had its model curricula, as well as the formal document $I S$ '97. In 1998, the Computer Society of the IEEE (Institute for Electrical and Electronic Engineers) and the ACM (Association for Computing Machinery) established the Joint Task Force on Computing Curricula 2001. This task force recognized the need for a multi-volume definition for computing curricula, with a volume for each of the computing disciplines of CS, IS, computer engineering (CE), and software engineering (SE). In 2004 this task force expanded this to include a volume for the IT computing discipline. In June 2004, the Joint Task Force released the Strawman Draft of Computing Curricula 2004, an overview report including a guide to undergraduate degree programs in computing for programs in CE, CS, IS, IT, and SE. (Joint Task Force, 2004)

The charge to the SIGITE Curriculum Committee was to produce the IT volume for this multivolume effort, often referred to as CC2001.

\section{Body of Knowledge}

The CS volume of CC2001 was officially accepted as the model toward which the SIGITE curriculum committee would be working (see www.computer.org/education/cc2001/final/index.htm). This volume of the CC2001 document defines 14 knowledge areas, which are additionally broken down into units and topics as necessary, defining what is termed the CS body of knowledge. In keeping with our agreement to work toward writing the IT volume of the CC, we next defined the body of knowledge for IT.

After several iterations, the knowledge areas presently defined for IT include the following twelve: IT Fundamentals; Human-Computer Interaction, Information Assurance and Security, Information Management, Integrative Programming \& Technologies, Networking, Programming Fundamentals; Platform Technologies, System Administration and Maintenance, System Integration and Architecture, Social and Professional Issues, and Web Systems and Technologies. Each of these knowledge areas has been further broken down into units and topics, and core hours have been assigned to each. A copy of the IT body of knowledge is included in the Appendix.

\section{Model Curriculum and IT Volume}

In April of 2005, the SIGITE curriculum committee completed the first draft of the IT model curriculum and posted it for public review and feedback. Although still in the draft stage, this model curriculum has broad support from the IT community, while details involved are still being worked on. A copy of this model curriculum is included in the IT volume of the $\mathrm{CC}$ document.

Also in April of 2005, the SIGITE curriculum committee completed the first draft of the IT volume of the $\mathrm{CC}$ document, and posted it for public review and feedback. The document is more than 100 pages long, so only a link to it is included in this paper. (See http://sigite.acm.org/activities/curriculum/).

\section{Accreditation}

As mentioned, the IT accreditation committee was formed at CITC-1 in December 2001. One of the first accreditation issues to be settled was the question of which accreditation agency we would go with. At the time, CS programs were accredited by the Computer Science Accreditation Board (CSAB), and computer engineering and computer engineering technology programs were accredited by the Accreditation Board for Engineering and Technology (ABET). However, this 
dilemma was soon settled when CSAB opted to discontinue accreditation activities and established that all future accreditations for CS programs would be handled through the Computing Accreditation Commission (CAC) of ABET.

The next question about accreditation dealt with the commission of ABET through which IT would accredit. Some members of SITE wished to affiliate academically with computing programs, and thus seek accreditation through CAC of ABET, while others wished to affiliate academically with engineering technology, and thus seek accreditation through the Technology Accreditation Commission (TAC) of ABET. At CITC-2 this issue was discussed in a plenary session and was then put to a vote. The membership voted decisively to affiliate with computing programs, and to seek accreditation through CAC of ABET.

The next step for the IT accreditation committee was to write the draft accreditation criteria. These criteria were brought in their original draft form to CITC-2, where they were also discussed in a plenary session. Discussion was open and insightful, and several modifications were made. After CITC-2, the accreditation committee made a few other changes as recommended at CITC-2 and the accreditation criteria were posted to the SITE website for all to review and comment (see www.citc.it.rit.edu).

Since the criteria were posted to the above website, a few additional changes have been recommended, discussed, and incorporated as necessary. The most significant change occurred because CAC took the decision to follow the lead of the other accreditation commissions within ABET, most notably EAC, and develop a set of general accreditation criteria for computing disciplines, to be supplemented by discipline specific accreditation criteria for such disciplines as computer science, information systems and information technology. The IT community was invited to participate in the formulation of the general accreditation criteria, and it did indeed do so. The general accreditation criteria have since been approved on first reading by the ABET board of directors and are available for inspection and comment from ABET's web site (www.abet.org/info prgs cac.html). In the Fall of 2004, three 4-year IT programs were visited for accreditation under the general computing criteria.

In the fall of 2003, the IT-specific accreditation criteria were submitted and posted for public review. After the required 1-year period, they have now been approved for accreditation visits, and three IT programs have applied to be accredited under these IT-specific criteria in the Fall of 2005.

\section{International Impact}

The ongoing work to define the IT curriculum has been presented at multiple international forums, including the International Conference on Engineering and Computer Education (ICECE) 2003 in Brazil (Lunt et al., 2003a), the International Conference on Engineering Education and Research (ICEER) 2004 in the Czech Republic (Lunt et al., 2004a), and the World Engineers' Convention (WEC) 2004 in China (Lunt et al., 2004b). During discussions at and after these presentations, it has become apparent that this work to formally define the IT curriculum will have an international impact. Most European and Middle-eastern countries are modeling their accreditation for computing programs after the work of the CAC of ABET, which for IT has been defined by our SIGITE accreditation committee. Additionally, the lead author is personally aware that China is using the products of the SIGITE curriculum committee as their starting point for defining IT.

\section{Conclusion}

The formation of an IT professional society (formerly SITE, now SIGITE), the completion of draft accreditation criteria, and the writing of model curriculum and a draft of the IT volume of 
the $\mathrm{CC}$ document, have all taken place in a comparatively short time. Having started in December 2001 , the entire process has taken only about $3 \frac{1}{2}$ years so far, and is nearing completion. Additionally, papers have been published which help define the IT academic discipline, especially as compared to the closely-related programs of information systems and computer science.

SIGITE is open to members from any academic programs, and is particularly interested in including members from IT programs across the nation and eventually the world. Participation on any of the committees is open to all SIGITE members.

\section{References}

Brown, B. (1968). Delphi process: A methodology used for the elicitation of opinions of experts. Rand Corp., Santa Monica, CA.

CSAB. (1997 May 28) Defining the computing sciences professions. Retrieved from http://www.csab.org/comp sci profession.html

Dalkey, N. (1967). The Delphi method: An experimental study of group opinion. Rand Corp., Santa Monica, CA.

Dalkey, N. (1969). The Delphi method: An experimental study of group opinion. Rand Corp., Santa Monica, CA.

Dalkey, N. \& Helmer, O. (1951). The use of experts for the estimation of bombing requirements: A project Delphi experiment. Rand Corp., Santa Monica, CA.

Dalkey, N., Rourke, D., Lewis, R., \& Snyder, D. (1972). Studies in the quality of life; Delphi and decision making. Lexington Books, Lexington, MA.

Joint Task Force for Computing Curricula. (2004). Overview report including a guide to undergraduate degree programs in computing. Strawman Rev 4, p. 18. http://www.acm.org/education/Overview_Draft_11-22-04.pdf

Lunt, B. M., Ekstrom, J. J., Lawson, E. A., Kamali, R., Miller, J., Gorka, S., \& Reichgelt, H., (2004a) Defining the IT curriculum: The results of the past $2 \frac{1}{2}$ years. Proceedings of the 2004 International Conference on Engineering Education and Research (iCEER), Olomouc, Czech Republic, proceedings on CD-ROM.

Lunt, B. M., Ekstrom, J. J., Lawson, E. A., Kamali, R., Miller, J., Gorka, S., \& Reichgelt, H., (2004b). Defining the IT curriculum: The results of the past 2 $\frac{1}{2}$ years. Proceedings of the 2004 World Engineers' Convention (WEC), Shanghai, China, 191-196.

Lunt, B. M., Reichgelt, H., Ashford, T., Phelps, A., Slazinski, E., \& Willis, C. (2002, September). An empirical comparison of baccalaureate programs in computing. CITC-3, Rochester, NY.

Lunt, B. M., Reichgelt, H., Ashford, T., Phelps, A., Slazinski, E., \& Willis, C. (2003a). An empirical comparison of baccalaureate programs in computing. Proceedings of the 2003 International Conference on Engineering and Computer Education (ICECE), Santos, SP, Brazil, proceedings on CD-ROM.

Lunt, B. M., Reichgelt, H., Ashford, T., Phelps, A., Slazinski, E., \& Willis, C. (2003b). What is the new discipline of information technology? Where does it fit? CIEC 2003, Tucson, AZ.

Reichgelt, H., Lunt, B. M., Ashford, T., Phelps, A., Slazinski, E., \& Willis, C. (2004). A comparison of baccalaureate programs in information technology with baccalaureate programs in computer science and information systems. Journal of Information Technology Education, 3, 19-34 


\section{Appendix \\ The Information Technology Body of Knowledge}

ITF. Information Technology Fundamentals (33 core hours)

ITF1. Pervasive Themes in IT (17)

ITF2. Organizational Issues (6)

ITF3. History of IT (3)

ITF4. IT and Its Related and Informing Disciplines (3)

ITF5. Application Domains (2)

ITF6. Applications of Math and Statistics to IT (2)

HCI. Human Computer Interaction (20 core hours)

HCI1. Human Factors (6)

HCI2. HCI Aspects of Application Domains (3)

HCI3. Human-Centered Evaluation (3)

HCI4. Developing Effective Interfaces (3)

HCI5. Accessibility (2)

HCI6. Emerging Technologies (2)

HCI7. Human-Centered Software (1)

IAS. Information Assurance and Security (23 core hours)

IAS1. Fundamental Aspects (3)

IAS2. Security Mechanisms (Countermeasures) (5)

IAS3. Operational Issues (3)

IAS4. Policy (3)

IAS5. Attacks (2)

IAS6. Security Domains (2)

IAS7. Forensics (1)

IAS8. Information States (1)

IAS9. Security Services (1)

IAS10. Threat Analysis Model (1)

IAS11. Vulnerabilities (1)

IM. Information Management (34 core hours)

IM1. IM Concepts and Fundamentals (8)

IM2. Database Query Languages (9)

IM3. Data Organization Architecture (7)

IM4. Data Modeling (6)

IM5. Managing the Database Environment (3)

IM6. Special-Purpose Databases (1)

IPT. Integrative Programming \& Technologies (23 core hours)

IPT1. Intersystems Communications (5)

IPT2. Data Mapping and Exchange (4)

IPT3. Integrative Coding (4)

IPT4. Scripting Techniques (4)

IPT5. Software Security Practices (4)

IPT6. Miscellaneous Issues (1)

IPT7. Overview of programming languages (1)

NET. Networking (20 core hours)

NET1. Foundations of Networking (3).

NET2. Routing and Switching (8)

NET3. Physical Layer (6)

NET4. Security (2)

NET5. Application Areas (1)

Notes:

NET6. Network Management

1. Order of Knowledge Areas: Fundamentals first, then ordered alphabetically.

2. Order of Units under each Knowledge Area: Fundamentals first (if present), then ordered by number of core hours.

PT1. Operating Systems (10)

PT6. Hardware

$\underline{\text { SA4. Administrative Domains }}$ (2)
PF. Programming Fundamentals ( 38 core hours)

PF1. Fundamental Data Structures (10)

PF2. Fundamental Programming Constructs (9)

PF3. Object-Oriented Programming (9)

PF4. Algorithms and Problem-Solving (6)

PF5. Event-Driven Programming (3)

PF6. Recursion (1)

PT. Platform Technologies (14 core hours)

PT2. Architecture and Organization (3)

PT3. Computer Infrastructure (1)

PT4. Enterprise Deployment Software

PT5. Firmware

SA. System Administration and Maintenance (11 core hours)

SA1. Operating Systems (4)

SA2. Applications (3)

SA3. Administrative Activities (2)

SIA. System Integration and Architecture (21 core hours)

SIA1. Requirements (6)

SIA2. Acquisition/Sourcing (4)

SIA3. Integration (3)

SIA4. Project Management (3)

SIA5. Testing and QA (3)

SIA6. Organizational Context (1)

SIA7. Architecture (1)

SP. Social and Professional Issues (23 core hours)

SP1. Technical Writing for IT (5)

SP2. History of Computing (3)

SP3. Social Context of Computing (3)

SP4. Teamwork Concepts and Issues (3)

SP5. Intellectual Properties (2)

SP6. Legal Issues in Computing (2)

SP7. Organizational Context (2)

(2)

SP8. Professional and Ethical Issues and Responsibilities

SP9. Privacy and Civil Liberties (1)

WS. Web Systems and Technologies (21 core hours)

WS1. Web Technologies (10)

WS2. Information Architecture (4)

WS3. Digital Media (3)

WS4. Web Development (3)

WS5. Vulnerabilities (1)

WS6. Social Software

Total Hours: 281 


\section{Programs Included in Comparative Study}

Brigham Young University, Provo (BYU)

Capella University

George Mason University (GMU)

Georgia Southern University (GSU)

Macon State College (MSC)

Pennsylvania College of Technology (PCT)
Purdue University, West Lafayette

Rochester Institute of Technology (RIT)

University of Baltimore (U of B)

University of Houston ( $\mathrm{U}$ of $\mathrm{H}$ )

University of South Alabama (U of SA)

\section{Biographies}

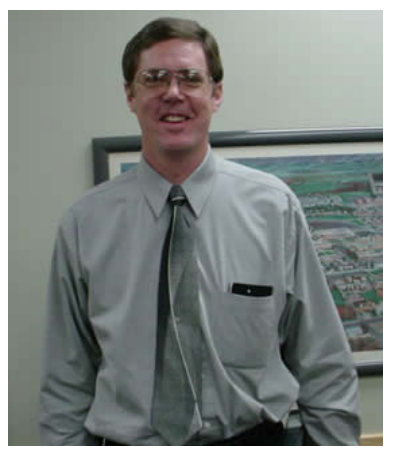

Barry M. Lunt is an Associate Professor of Information Technology at Brigham Young University in Provo, UT. Dr. Lunt received a B.S. and an M.S. degree in EET from BYU, and a Ph.D. in Occupational and Adult Education from Utah State University in Logan, UT. He has spent seven years in industry as a design engineer. His present research emphases are the physical design of electronic circuits and systems, IT curriculum, and engineering education.

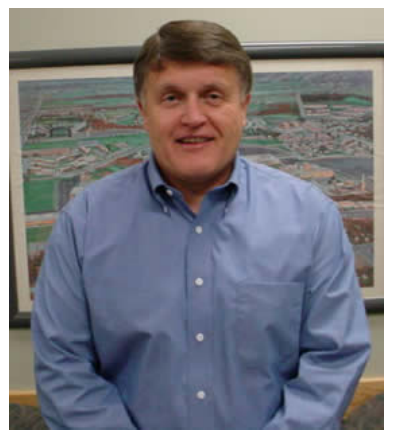

Joseph J. Ekstrom (Ph. D. Computer Science, BYU 1992) has been Associate Professor of Information Technology at BYU since 2001. During 30 years of industrial experience he held positions from developer through senior management. His research interests include network and systems management, distributed computing, system modeling and architecture, system development, and IT curriculum and instruction.

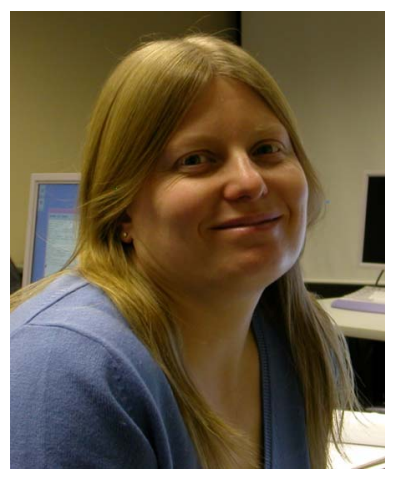

Sandra Gorka is an Assistant Professor of Information Technology at the Pennsylvania College of Technology (PCT) in Williamsport, Pennsylvania. Dr. Gorka received a B.A. in mathematics from Shippensburg University, and an M.S. degree and Ph.D. in mathematics and topology from the University of Delaware. She has worked for several years as a private consultant. Her present research interests include IT curriculum, pedogogy and education. 

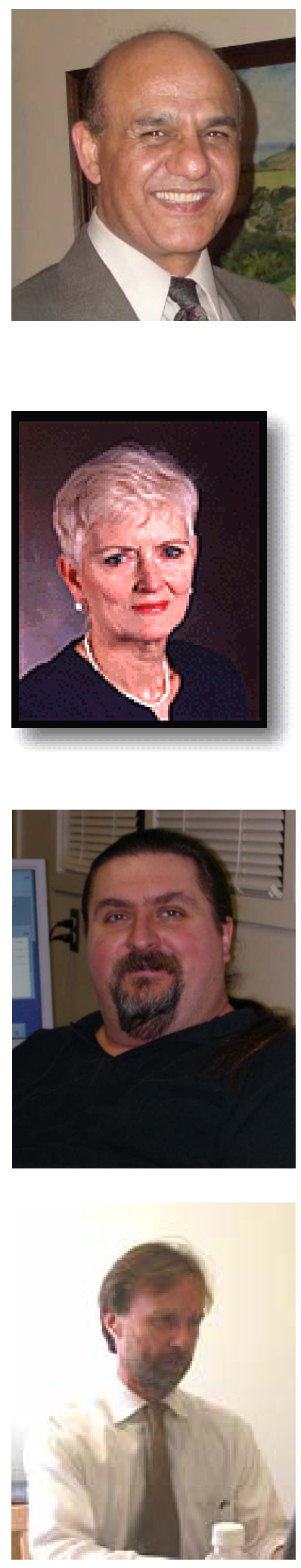

Reza Kamali is an Associate Professor and department head of Information Systems/Information Technology department at Purdue Calumet University, Hammond, IN. Dr. Kamali received a B.A. in Economics from University of Tehran, Iran, an M.S. in Computer Science and an M.S. in Mathematical Sciences, both from University of Arkansas, and a Ph.D. in Mathematics from Drexel University. His present research emphasis is IT curriculum.

Edith A. Lawson is the Department Chair of the Information Technology Department at the Rochester Institute of Technology in Rochester, New York. She completed a BS degree in Economics at Wisconsin State University and an MS in Business and an MS in Computer Science at the Rochester Institute of Technology. Her primary areas of interest are database programming, E-commerce and applied computing education.

Jacob R. Miller is an Associate Professor of Computer Science at the PCTin Williamsport, Pennsylvania. He earned his B.A. in mathematics at Shippensburg University and his M.S. and Ph.D. degrees at the University of Delaware in mathematics and dynamical systems. He has spent seven years working in industry for IBM in inventory planning and distribution. His present research is in IT education and curriculum as well as network security.

Han Reichgelt is associate professor of information technology and acting chair of the department of information technology at Georgia Southern University. He holds first degrees in philosophy and psychology from the University of Nijmegen in the Netherlands and a PhD in Cognitive Science from the University of Edinburgh. His main research interests are information technology and computer science education, e-commerce, and IT and economic development. 